\title{
РЫНОК СТРУКТУРНЫХ ОБЛИГАЦИЙ В РОССИИ: СОСТОЯНИЕ И ПЕРСПЕКТИВЫ РАЗВИТИЯ
}

\author{
(C) 2021 Гусева Ирина Алексеевна \\ кандидат экономических наук, доцент, \\ профессор Департамента банковского дела и финансовых рынков Финансового факультета \\ Финансовый университет при Правительстве Российской Федерации, Россия, Москва \\ E-mail: iaguseva@fa.ru \\ ORCID 0000-0001-7707-1585 \\ () 2021 Турченкова Мария Михайловна \\ магистрант Финансового факультета \\ Финансовый университет при Правительстве Российской Федерации, Россия, Москва \\ E-mail: mariaturchenkova97@gmail.com
}

Статья посвящена новому сегменту российского фондового рынка - структурным облигациям. Показаны особенные черты этого финансового инструмента по сравнению с классическими облигациями, проанализировано текущее состояние и проблемы развития рынка структурных облигаций, определены тенденции и перспективы его развития.

Ключевые слова: российский фондовый рынок, структурная облигация, защита капитала, структурные продукты, базовый актив

В периоды низких процентных ставок и высокой степени неопределенности на финансовом рынке определение целей инвестирования кажется одной из наиболее сложных вопросов для инвесторов. С одной стороны, существует потребность в защите капитала и более консервативном подходе инвестирования, с другой стороны, есть желание принимать импульсивные решения для получения большего дохода. Каждый инвестор старается подобрать собственный баланс разных активов в портфеле по приемлемому уровню риска и желаемой доходности. Данная задача не является простой. Для ее решения на российском финансовом рынке был создан новый инструмент, который позволяет установить уровень защиты капитала, снизить риски, диверсифицировать портфель и дать возможность инвесторам получить большую доходность по сравнению с другими финансовыми инструментами - структурные облигации.

Как правило, структурные облигации сочетают в себе безрисковую (или низкорисковую) часть в виде депозитов или высоконадежных долговых ценных бумаг и рисковую часть, представленную в виде опционов на акции, корзину активов, курсы валют, индексы, товары и т.д.

В мире принято считать структурной облигацией (нотой) ценную бумагу, выпущенную

финансовыми институтами, доходность которых зависит от значений базового актива, заложенного в структуру ноты - от цены акции или корзины акций, товаров, валют, индексов (определение SEC - Американской комиссии по ценным бумагам и биржам) [13]. Видим, что доход по таким инструментам связан с эффективностью базового актива.

На практике выделяют несколько видов структурированных облигаций:

1. с полной защитой капитала;

2. с с частичной защитой капитала;

3. без защиты капитала.

Стоит упомянуть, что согласно российскому законодательству структурными облигациями являются облигации с неполной защитой капитала, обычно эмитенты при выпуске называют их инвестиционными (в эмиссионных документах - биржевыми) облигациями. В рамках данной работы инструменты с полной защитой капитала, дополнительный доход которых будет зависеть от наступления или ненаступления определенного события с гарантированной выплатой номинала будем рассматривать как структурные облигации с полной защитой капитала.

Введение структурных облигаций на российском рынке началось с пояснительной записки 
к проекту Федерального закона «О внесении изменений в Федеральный закон «О рынке ценных бумаг» в части регулирования структурных расписок» [2] в 2018 году. В данном законопроекте была обозначена актуальность структурных облигаций (структурных расписок в первой редакции проекта) с частичной защитой капитала, которая выражалась в потребности и востребованности населения в данных финансовых инструментах. В условиях снижения процентных ставок по депозитам и классическим облигациям инвесторы хотят найти альтернативу с более высокой доходностью. Данная тенденция является актуальной не только в России, но и во всем мире. На дату первой версии законопроекта доля структурных продуктов с частичной защитой капитала составляла около 70\% структурных продуктов в целом, каждый год объем продаж составлял около 500 млрд. долларов. Российские инвесторы все чаще покупали структурные продукты у иностранных эмитентов, благодаря чему обозначилась потребность в регулировании данного инструмента на российском рынке, так как до введения поправок в ФЗ «О рынке ценных бумаг» в 2018 году, выпускать облигации с неполной защитой капитала в России запрещалось на законодательном уровне.

Введение регулирования на российском рынке структурных облигаций также было связано прежде всего из-за отсутствия регулирования при тенденции развития и распространения данного инструмента и санкционных рисков в сторону некоторых участников рынка.

После введения нового финансового инструмента на российский рынок и одновременным притоком населения на фондовый рынок регулятор столкнулся с рядом проблем в отношении продаж и недопонимания инвесторами структурных облигаций с полной защитой капитала (инвестиционными облигациями). На что Банк России 15 декабря 2020 года отреагировал настоятельной рекомендацией финансовым организациям не продавать сложные инвестиционные продукты неквалифицированным инвесторам до введения тестирования. Рынок в свою очередь также столкнулся с рядом проблем относительно выпуска и продажи структурных облигаций.

Проблемы, которые возникли между регулятором и рынком при выпуске и распространении структурных облигаций, пути их решения и перспективы развития:
1. Неправильная продажа сложных финансовых инструментов инвесторам. На фоне снижающихся процентных ставок и желании инвесторов получить больший доход некоторые банки начали предлагать неквалифицированным инвесторам альтернативу в виде структурных облигаций с полной защитой капитала. Заявленная доходность по данным инструментам была значительно выше доходности по депозитам и была сформирована на основе успешно погашенных выпусков структурных облигаций, что не является гарантией получения такого дохода в будущем, о чем некоторые инвесторы могут не догадаться. В том числе, как правило, эмитенты не упоминали о том, что на вторичном рынке продать такой инструмент можно только с большим дисконтом к номинальной стоимости, тем самым формируя ложные представления о продукте [5].

2. Длительная и дорогая процедура выпуска структурных облигаций по российскому законодательству. Выпуск структурных облигаций в 2,5-3 раза дороже, чем выпуск по иностранному праву [11]. Также проблема начала стоять в потере интереса инвесторов к инвестиционной стратегии облигации (около 1-2 месяцев происходит процедура согласования эмиссионных документов с Банком России) [6]. Такой порядок не прибавляет интереса эмитентам выпускать рассматриваемый финансовый инструмент по российскому праву. Несмотря на это Банк России не стремится предавать полномочия по регистрации выпусков Московской бирже из-за недостаточной развитости инструмента.

3. Выпуск и регулирование структурных облигаций. Участниками рынка и регулятором было предложено ряд критериев в части выпуска и регулирования структурных облигаций, по пунктам которых стороны не сразу пришли к единому мнению.

Например, предлагается ввести такой критерий как уровень предельных потерь инвестоpa, который будет зависеть от срока обращения финансового инструмента. Но данный фактор не будет устанавливаться, если базовый актив будет высококачественным.

Также Банк России отметил, что не эмитент будет выбирать способ выплаты по облигации, а инвестор - то есть за владельцем структурной облигации может быть поставлен выбор выплаты денежными средствами или качественным 
базовым активом (актив, который может покупать неквалифицированный инвестор).

Число контрольных лиц облигации должно быть не более четырех.

Эмитент должен раскрывать информацию о базовом активе, в противном случае у инвестора появится возможность досрочно погасить облигацию.

Структурная облигация не должна содержать большое плечо.

Базовый актив должен быть понятен неквалифицированному инвестору, в связи с чем связано введение тестирование на знание продукта. Ввод тестирования воспринят рынком больше как негативный фактор нежели позитивный, так как результаты после проведенных опросов брокерами и некоторыми исследователями показали, что в среднем 20-40\% инвесторов предпочтут перейти к зарубежному брокеру, чем проходить тестирование на знание инструментов. Что повлияет на рентабельность некоторых брокеров, которые ориентированы на физических лиц [12].

Успешное прохождение тестирования также может оказать на инвестора воодушевляющее воздействие, что может спровоцировать совершать более рискованные сделки, итогом которых может оказаться разочарование в фондовом рынке.

Также ведется разработка паспорта продукта (аналог европейского KID) на 2-3 страницы, в котором будет содержаться вся необходимая информация о данном финансовом инструменте, тем самым регулятор намеревается повышения качества предоставления информации в целях полного и приемлемого информирования инвесторов.

4. Низкая доходность по структурным облигациям. Из анализа 78 погашенных выпусков структурных облигаций с полной защитой капитала (в основном за 2019 и 2020 год в большинстве сроком не более года) 30 выпусков не принесли дополнительного дохода инвесторам, что составляет $38,5 \%$ совокупности. Средняя реализованная доходность составила 4,69\% годовых, что является величиной меньшей, чем максимальная процентная ставка по депозитам за данный период, которая была между 4-7,5\% годовых [1]. Данные по реализованной доходности структурных облигаций показаны на Графике 1 . Такие результаты могут разочаровать инвесторов, в последствие чего сократится спрос на данные инвестиционные продукты. K тому же может произойти падение доверия к фондовому рынку в целом.

Стоит понимать, что предугадать будущую потенциальную доходность по данным инструментам на основе результатов предыдущих выпусков будет совсем не корректно, но данную практику использовали эмитенты при продажах облигаций до получения Информационного письма от Банка России 15 декабря 2020 года.

5. Непонимание инвесторами финансового инструмента, включая формулу расчета дополнительного дохода. Неквалифицированные инвесторы расценивают структурные облигации и/или инвестиционные облигации как надежный инструмент, который способен приносить потенциально высокую доходность на основе динамики базового актива, не всегда учитывая того, что формула определения доходности по базовому активу не всегда совпадает с формулой определения дополнительного дохода по структурной облигации (результат последнего, как правило, значительно ниже). Итогом чего может стать недовольство инвесторов в новом инструменте и в фондовом рынке в целом - сложная конструкция, условия выплаты, определение формулы дохода по инструменту, большие ко-

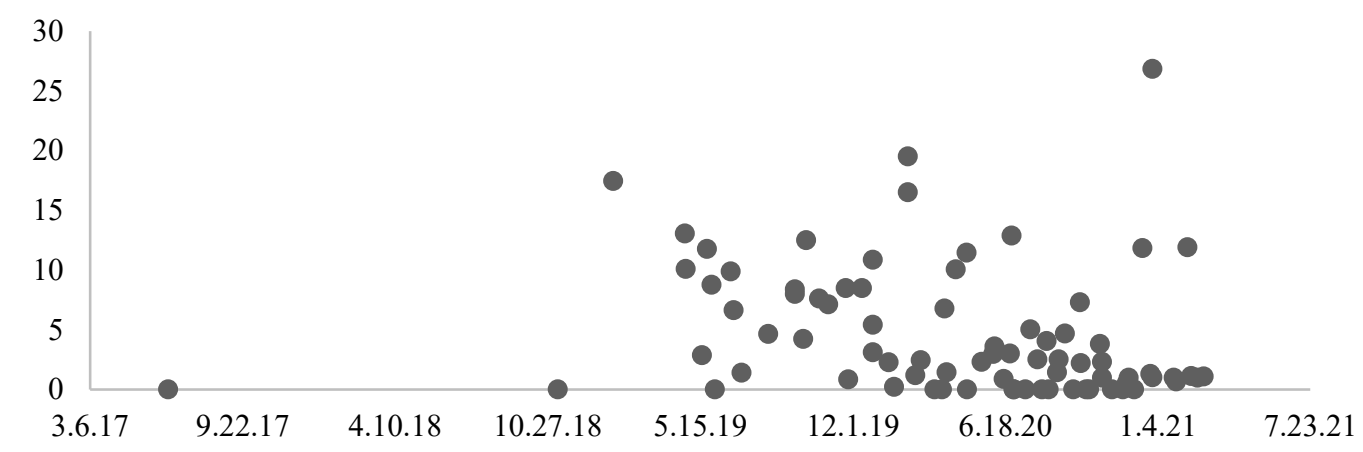

График 1. Реализованная доходность структурных облигаций на российском рынке Источник: составлено авторами на основании данных cbonds.ru [9] 
миссии, практическая невозможность продать инструмент ранее срока погашения на вторичном рынке даже по номиналу - все может привести к разочарованию инвесторов в инвестировании в фондовый рынок.

6. Конструкциии структурных облигаций, не учитывающие волатильность российского рынка.

Эмитенты используют различные варианты конструирования. В рамках данной работы приведем основные и распространенные варианты образования структурных облигаций.

1) Структурные облигации, которые участвуют в динамике базового актива. То есть у данных инструментов присутствует определенный коэффициент участия, от которого зависит итоговый финансовый результат продукта. Как правило, в конструкции содержится всего один базовый актив в виде единственного инструмента.

2) Структурные облигации с установленным диапазоном (range accrual). По данному виду структурной облигации дополнительный доход начисляется по мере нахождения базового актива в заранее установленном диапазоне цен. Если базовый актив находится вне диапазона, то доход в данный период не начисляется.

3) Облигации с «эффектом памяти» купона. При такой конструкции, как правило, базовым активом является корзина акций. По такой облигации, как правило, устанавливается определенный барьер, до значения которого не должны опуститься базовые активы для выплаты дохода. «Эффект памяти» заключается в том, что если в первый купонный период хотя бы одна из акций корзины упадет ниже порогового значения, то выплата купона по данному периоду может осуществиться в следующем купонном периоде (за 2 периода - по текущему и предыдущему и так далее) в случае, если все акции удовлетворяют требованиям выплаты дополнительного дохода.

4) Структурные облигации с американским барьером. По такому виду облигации дополнительный доход выплачивается в том случае, если базовый актив не касался уровня барьера в течение всего периода обращения. В обратном случае дополнительный доход не выплачивается.

5) Структурные облигации с европейским барьером. В данном случае дополнительный доход выплачивается в случае, если на дату погашения облигации базовый актив преодолел или наоборот не достиг определённый, заранее установленный уровень барьера.

В основном на российском рынке инвесторы получают доход по структурным облигациям с заранее установленным диапазоном (range accrual). Обычно данную конструкцию используют, когда рынок находится во флэте, но в нашей ситуации данная стратегия срабатывает из-за того, что шанс базового актива попасть в определенный диапазон выше, чем предугадать его значение через определенный промежуток времени. Данный тип структурных облигаций на российском рынке широко распространён.

Таким образом, эмитентам и инвесторам стоит обращать внимание на высокую волатильность российского рынка, особенность которого делает практически невозможным шанс угадать значение и даже движение актива, особенно на долгий срок. Для наглядности можно привести пример из теории вероятности. Предположим, что эмитент выпустил облигацию, выбрав в качестве базовых активов 4 акции, и поставил условие, что дополнительный доход будет выплачен, если ни одна из акций за три года не упадет ниже значения 65\% от первоначальной цены. На первый взгляд, такое событие кажется маловероятным, особенно в условиях тенденции роста рынка. Допустим, что вероятность того, что цена каждой акции за три года упадет ниже барьерного уровня, составляет 20\%, что является довольно оптимистичным прогнозом. Тогда вероятность того, что цены всех 4 акций останутся выше порогового уровня, составляет $80 \%$ *80\%*80\%*80\%= 40,96\%. А вероятность получить убыток по такой облигации составляет 59,04\% соответственно.

7. Практика построения стратегии доверительного управления в инвестирование структурных облигаций своей финансовой группы. Уплата инвестором двойной комиссии.

Некоторые стратегии доверительного управления были основаны на покупке структурных облигаций, эмитентом которых являлся член одной финансовой группы, что и доверительный управляющий (крупнейшая стратегия привлекла 57 млрд. руб. средств физических лиц по состоянию на 30 ноября 2020 года) [5]. Получается, что при такой схеме инвестор уплачивает двойную комиссию - комиссия за доверительное управление и комиссия в составе структурной облигации. Банк России запретил привлечение клиентов в такую стратегию инвестирования. 
8. Не завершенная корректировка законодательства. Например, до сих пор идут обсуждения в части определения регулирования продажи структурных продуктов неквалифицированным инвесторам, постпродажного регулирования. Законодательство на данном этапе приводит общие формулировки без какой-либо конкретики - такие как «предоставление информации должно осуществляться в полном объеме для того, чтобы инвестор смог оценить риск и принять решение в покупке инструмента».

9. Байбэк структурных облигаций. НАУФОР и участники рынка выражают протесты в выкупе облигаций эмитентом по требованию Банка России, так как в дальнейшем данная практика может привести к отказу в выпуске структурных облигаций из-за существования риска потенциальных потерь [10].

10. Недостаточная ликвидность рынка. Как правило, если все-таки существует вторичный рынок структурных облигаций, то из-за сложности продукта облигации обращаются со значительными скидками к цене покупки. Чем больше срок до погашения инструмента, тем больше вероятность возникновения желания досрочно продать его, но в связи с недостаточной развитостью инструмента такая возможность не всегда предоставляется. Данный фактор затормаживает процесс развития структурных облигаций, нежели ускоряет его.

Лидерами размещений структурных облигаций на российском рынке являются Сбербанк (59\% рынка), БКС (24\% рынка) и ВТБ (6\% рынка). Данные по размещениям основных эмитентов облигаций приведены в Таблице 1.

Если рассмотреть динамику выпусков структурных облигаций в России по годам, то можно наблюдать почти полную зависимость объема в обращении и количества выпусков, что может говорить нам о том, что объем в обращении увеличивался не за счет увеличения номинала, а за счет новых эмиссий (График 2). Для корректности сравнения все валюты переведены в единую - долл. США.

В настоящий момент в России обращается более 700 выпусков структурных облигаций. Наиболее популярными базовыми активами являются корзина акций (36\% совокупности), индекс (22\% совокупности). Исходя из анализа 767 выпусков выпущенных облигаций.

По состоянию на 1 марта 2021 года объем рынка структурных облигаций составляет около 516 млрд. рублей. Сравним с объемом корпоративных облигаций - 16065,9 млрд. рублей [9]. В основном в России выпускаются структурные

Таблица 1. Лидеры размещения структурных облигаций 2016-2020 гг., количество выпусков

\begin{tabular}{|l|c|c|c|c|c|}
\hline & 2016 & 2017 & 2018 & 2019 & 2020 \\
\hline Сбербанк России & 1 & 1 & 33 & 134 & 182 \\
\hline ВТБ & & & 3 & 5 & 114 \\
\hline BrokerCreditService Structured Products & 2 & 18 & 25 & 57 & 74 \\
\hline
\end{tabular}

Источник: составлено авторами на основании данных cbonds.ru [9]

$$
\begin{aligned}
& 5000,00 \\
& \text { 寻 } 4000,00 \\
& \text { 宊 } 3000,00 \\
& \text { คี } 2000,00 \\
& \text { 萝 } 1000,00 \\
& 0,00
\end{aligned}
$$

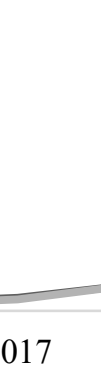

— Объем в обращении, долл. США

График 2. Зависимость объема в обращении и количества выпусков структурных облигаций Источник: составлено авторами на основании данных cbonds.ru [9] 
облигации с полной защитой капитала. 9 выпусков структурных облигаций с частичной защитой капитала обращается на Московской бирже

На российском рынке мы наблюдаем тенденцию изменения отношения инвесторов к риску ради потенциальной возможности получить больший доход, в связи с чем структура выплат по облигациям начинает усложняться и приобретать новые формы, что является закономерным ответом на вызовы развития финансового рынка в целом. Увеличивается приток инвесторов на фондовый рынок, включая активных участников торгов.

На данном этапе российское регулирование осторожно относится к продажам данного инве- стиционного продукта неквалифицированным инвесторам и вносит поправки в Закон, придерживаясь международного опыта, в частности опыта Европы. Например, тестирование инвесторов на знание сложного продукта, категоризация инвесторов, разработка паспорта продукта (аналог KID) как и в законодательстве Европы. На сегодняшний день продажа структурных продуктов доступна только квалифицированным инвесторам.

Таким образом, Россия осторожно приспосабливается к мировым тенденциям развития структурных облигаций, постепенно вводит новый инструмент на рынок, пытаясь избежать мисселинга и ошибок других стран.

\section{Библиографический список}

1. Динамика максимальной процентной ставки (по вкладам в российских рублях) десяти кредитных организаций, привлекающих наибольший объём депозитов физических лиц. [Электронный ресурс].- Центральный банк РФ - Режим доступа: https://www.cbr.ru/statistics/avgprocstav/ (дата обращения 07 апреля 2021)

2. Законопроект №№ 211550-7 «О внесении изменений в Федеральный закон «О рынке ценных бумаг» в части регулирования структурных облигаций» [Электронный ресурс].- Система обеспечения законодательной деятельности - Режим доступа: https://sozd.duma.gov.ru/bill/211550-7 (дата обращения 07 апреля 2021)

3. Конференция «Структурные продукты» [Электронный ресурс].- Национальная ассоциация участников фондового рынка - Режим доступа: https://www.naufor.ru/tree.asp?n=17322 (дата обращения 07 апреля 2021)

4. О рынке ценных бумаг: [Федеральный закон 22.04.1996 N 39-Ф3: принят ГД 20 марта 1996].- КонсультантПлюс.- Режим доступа: http://www.consultant.ru/document/cons_doc_LAW_10148 (дата обращения 07 апреля 2021)

5. О чем говорят тренды. Макроэкономика и рынки. Бюллетень Департамента исследований и прогнозирования. Январь 2021. [Электронный ресурс].- Центральный банк РФ - Режим доступа: http://www.cbr.ru/ collection/collection/file/31939/bulletin_21-01.pdf (дата обращения 07 апреля 2021)

6. Обзорный доклад. Структурные облигации в России: новый инструмент на российском финансовом рынке. [Электронный ресурс]. - Национальная финансовая ассоциация - Режим доступа: https://new.nfa.ru/ upload/iblock/8cc/Strukturnye_obligatsii_v_Rossii_novyy_instrument_na_rossiyskom_finansovom_rynke.pdf (дата обращения 03 апреля 2021)

7. Онлайн-конференция «Структурные продукты» [Электронный ресурс] / НАУФОР, Московская биржа - Режим доступа: https://www.moex.com/e16968/ (дата обращения 07 апреля 2021)

8. Основные направления развития финансового рынка Российской Федерации на период 2019-2021 годов. [Электронный ресурс].- Центральный банк РФ - Режим доступа: http://www.cbr.ru/content/document/ file/71220/main_directions.pdf (дата обращения 07 апреля 2021)

9. Поиск облигаций [Электронный ресурс] / Финансовое информационное агентство Cbonds.- Режим доступа: https://premium.cbonds.ru/bonds/?emitent_country_id=0-2\&status_id=5-1z141z4\&structured_note=1 \&securitisation_ne $=1 \&$ mortgage_bonds_ne $=1$ \&green_bonds_ne $=1$ \&euro_commercial_paper_ne $=1$ \&order=document\&dir=asc \& (дата обращения 07 апреля 2021)

10. Профучастники просят смягчения. ЦБ предложено допустить всех инвесторов до простых структурных продуктов. [Электронный ресурс] / Газета «Коммерсантъ» № 12 от 26.01.2021, стр. 8 - Режим доступа: https://www.kommersant.ru/doc/4662027 (дата обращения 07 апреля 2021)

11. Риск - структурное дело. [Электронный ресурс].- Издательский дом Коммерсантъ - Режим доступа: https://www.kommersant.ru/doc/4244293 (дата обращения 07 апреля 2021) 
12. Частных инвесторов разделят на две категории [Электронный ресурс] / Информационное агентство Ведомости - Режим доступа: https:/www.vedomosti.ru/economics/articles/2020/07/17/834780-investitsii-riska (дата обращения 03 апреля 2021)

13. Investor Bulletin: Structured Notes. [Электронный ресурс] - Securities and Exchange Commission - Режим доступа: https://www.sec.gov/oiea/investor-alerts-bulletins/ib_structurednotes.html (дата обращения 07 апреля 2021)

14. Structured Notes with Principal Protection: Note the Terms of Your Investment. [Электронный pecypc] - Securities and Exchange Commission - Режим доступа: https:/www.sec.gov/investor/alerts/structurednotes.htm (дата обращения 07 апреля 2021) 